\title{
CULTIVO E ANÁLISE DA COMPOSIÇÃO QUÍMICA DO COGUMELO DO SOL (AGARICUS BLAZEI MURRIL)
}

\section{CULTIVATION AND CHEMICAL ANALYSIS OF THE SUN MUSHROOM (AGARICUS BLAZEI MURRIL)}

\author{
Cristina Keiko Rebonato Shibata ${ }^{1}$, Ivo Mottin Demiate ${ }^{2}$
}

1 Universidade Estadual de Ponta Grossa, Campus em Uvaranas, Curso de Agronomia, Ponta Grossa, PR, Brasil.

2 Autor para contato: Universidade Estadual de Ponta Grossa - UEPG, Campus em Uvaranas, Departamento de Engenharia de Alimentos, Ponta Grossa, PR, Brasil;

(42) 220-3268; e-mail:demiate@interponta.com.br

Recebido para publicação em 20/08/2003

Aceito para publicação em 11/10/2003

\section{RESUMO}

O Agaricus blazei, natural da Mata Atlântica de São Paulo, vem sendo relatado como produto com propriedades medicinais, utilizado como complemento alimentar. Devido a escassez de informações e relatos técnico-científicos sobre o cultivo e propriedades químicas, este trabalho teve como objetivos conhecer as técnicas de produção e inoculação de Agaricus blazei, fazer o acompanhamento das etapas de produção e analisar os materiais obtidos de alguns produtores de Castro-PR, determinando a composição química do píleo e da estirpe, em diferentes tamanhos. As técnicas de produção de grãos colonizados foram acompanhadas no Módulo de Cogumelos da UNESP (Botucatu, São Paulo) determinação da composição química dos corpos de frutificação de Agaricus blazei, foi realizada no Laboratório de Tecnologia de Alimentos, da UEPG (Ponta Grossa, Paraná). A umidade foi determinada após secagem em estufa a $105^{\circ} \mathrm{C} / 5 \mathrm{~h}$. O teor de lipídios foi obtido por extração com éter de petróleo em Soxhlet. As proteínas foram quantificadas pelo método de micro-Kjeldahl. Após suspensão em água deionizada de uma quantidade de material triturado, mediu-se o pH com potenciômetro e determinou-se a acidez por titulação com $\mathrm{NaOH}$ 0,1N. O teor de cinzas foi determinado após queima em mufla a $550^{\circ} \mathrm{C} / 6 \mathrm{~h}$. As fibras foram quantificadas segundo o método de Weender e o teor de carboidratos, calculado por diferença. Comparando-se as duas partes do corpo de frutificação, observou-se maior teor de proteínas no píleo e de carboidratos na estirpe.

Palavras-chave: composição química, píleo, estirpe, cogumelo do sol 


\begin{abstract}
The Agaricus blazei, native from the Atlantic Forest of São Paulo State is being described as a food supplement with medicinal interest. Due to the lack of scientific information in relation to its cultivation and also to its chemical characteristics, this study was developed in order to get acquainted with the cultivation techniques from the laboratory to the field, to observe the cultivation and analyze the mushrooms produced in Castro (Paraná). The chemical composition of the different morphological parts of the mushrooms was evaluated, at different growth stages. The laboratorial techniques were observed at the Mushroom Module UNESP (Botucatu, São Paulo). The chemical composition of the mushrooms was analyzed at the Food Technology Laboratory of UEPG (Ponta Grossa, Paraná). The moisture content was measured after oven drying at $105^{\circ} \mathrm{C}$ for 5 hours. Lipids were quantified by means of solvent extraction and proteins by the micro Kjeldahl method. After making a water suspension of the ground material, the $\mathrm{pH}$ was measured by using a potentiometer, and the acidity, by titration with $0.1 \mathrm{~N} \mathrm{NaOH}$. The ash content was found after burning the samples at $550^{\circ} \mathrm{C}$ for 6 hours. The fiber content was determined following the Weender method and the carbohydrates were calculated by difference. Comparing the different parts of the mushrooms, higher protein contents were found in the pileus and higher carbohydrate contents in the stipe.
\end{abstract}

Key words: chemical composition; pileus; stipe; sun mushroom

\section{Introdução}

No Brasil, o consumo de cogumelos comestíveis vem crescendo significativamente devido ao reconhecimento do seu alto valor nutritivo e ao aumento da oferta, tornando o produto mais popular e acessível, sendo os principais cogumelos cultivados o Agaricus bisporus Lange (champignon), o Lentinula edodes Berk. (shiitake) e espécies do gênero Pleurotus (Eira e Minhoni, 1997).

As maiores barreiras encontradas na comercialização de cogumelos no Brasil estão ligadas à crença popular quanto à sua natureza venenosa, preço, hábito alimentar e ao cultivo com baixa produtividade. De acordo com Chang (1998), os cogumelos comestíveis representam 50\% da população de macrofungos e os venenosos apenas 10\%. A melhor compreensão da natureza biológica e o desenvolvimento de técnicas de cultivo avançadas têm contribuído para a diminuição do preço e aumento da produtividade. Além disso, aplicando-se as técnicas de melhoramento genético pode-se pro- duzir cogumelos de forma uniforme, com qualidade, em diversos substratos e ambientes (Elliott, 1987). Um dos principais fatores que tem contribuído para o aumento do consumo de cogumelos no Brasil é a maior procura por alimentos "naturais", sem defensivos agrícolas, com menor índice de gordura e maior de proteínas, além de propriedades terapêuticas preventivas e/ou curativas.

Os cogumelos têm um grande potencial, tanto para o consumo doméstico quanto para exportação, se mantidos os padrões de qualidade exigidos nos mercados internacionais. A bioconversão dos resíduos de biomassa lignocelulósica em alimentos e outros produtos de interesse econômico tem causado impacto positivo e as predições são de que esse impacto continuará aumentando (Chang, 1998).

Os cogumelos, como os outros fungos, não utilizam clorofila e são organismos não-verdes. Eles não podem converter a energia solar em matéria orgânica como as plantas, mas podem converter enormes quantidades de materiais lignocelulósicos, considerados resíduos agrícolas ou florestais, em 
alimento humano, ração para animais e fertilizantes. Por conseguinte, pode-se chamar o desenvolvimento sustentável gerado pelo cultivo de cogumelos de "a revolução não-verde", que, consolidada por um pacote projetado de tecnologias multidisciplinares, pode auxiliar na geração de um crescimento econômico eqüitativo, e na proteção e recuperação do meio ambiente (Herrera, 2001).

Bano e Rajarathnam (1988) e Eira e Minhoni (1997) ressaltaram a importância do cogumelo convencional como fonte alternativa de proteínas. Segundo os autores, comparativamente, um boi de $500 \mathrm{~kg}$ e o equivalente vegetal de $500 \mathrm{~kg}$ de soja convertem em energia e produzem, respectivamente, $500 \mathrm{~g}$ e $50 \mathrm{~kg}$ de proteína/dia, enquanto o mesmo peso em leveduras tem a capacidade de produzir $50000 \mathrm{~kg} / \mathrm{dia}$.

Poppe (2000) enumerou como benefícios diretos da conversão de resíduos em cogumelos: a provisão de alimentos, a criação de empregos, a melhoria da renda familiar, o controle na geração de resíduos, limpeza nos campos, florestas e margens de estradas, proteção da flora natural dos cogumelos, prevenção de incêndios florestais, e uso do substrato de cogumelos como composto para jardim ou horta.

De acordo com Sette (1994), qualidade de um produto agropecuário significa um produto limpo, higiênico, de sabor e odor agradáveis, com teores de proteínas, vitaminas, amido, gorduras, entre outros, maximizados ou minimizados conforme a finalidade, com tamanho, cor, forma e consistência ideais, padronizados puros, com umidade ideal.

Dada a escassez de informações ou relatos técnico-científicos sobre o cultivo de Agaricus blazei, este trabalho foi realizado em etapas, tendo como objetivos:

- Conhecer técnicas de produção e inoculação em grãos de cereais;

- fazer acompanhamento da produção, desde o cultivo até a comercialização;

- analisar materiais obtidos de diferentes produtores da cidade de Castro, determinando a composição química dos corpos de frutificação em diferentes tamanhos: pequeno de aproximadamente $4 \mathrm{~cm}$ de comprimento e grande, de 5 a $12 \mathrm{~cm}$ de comprimento, determinando-se separadamente a composição química do píleo e da estirpe.

\section{Revisão de literatura}

O reino dos fungos, com mais de um milhão e meio de espécies, algumas delas microscópicas, é ainda quase desconhecido pela ciência. Apesar do pouco conhecimento que se tem sobre os fungos, reconhece-se que entre eles há muitos que já se tornaram imprescindíveis para a saúde humana, uma vez que contribuem de forma decisiva para a preservação da diversidade biológica do nosso planeta (Herrera, 2001).

De acordo com Braga (1999), a classificação sistemática do A. blazei é a seguinte:

- Divisão: Basidiomycota

- Sub-divisão: Homobasidiomycetidae

- Ordem: Agaricales

- Família: Agaricaceae

- Gênero: Agaricus

- Espécie: Agaricus blazei

Atualmente são conhecidas mais de dez mil espécies de cogumelos, entretanto somente cerca de duas mil, pertencentes a pelo menos 30 gêneros, são consideradas comestíveis. Destas, 20 são cultivadas comercialmente e menos de 10, são industrializadas (Braga et al., 1998).

O consumo de cogumelos no país ainda é muito pequeno em relação ao dos povos europeu e asiático. Entretanto, nos últimos anos, a procura por cogumelos comestíveis vem aumentando e ganhando destaque, em virtude do seu sabor refinado, valor nutritivo e, ainda, pelo potencial de uso medicinal (Braga et al., 1998).

Dentre as espécies cultivadas, destaca-se o Agaricus blazei que, devido ao fato de ser relacionado como um produto com propriedades medicinais, tem despertado grande interesse por parte das 
comunidades médica e científica (Herrera, 2001).

O cogumelo Agaricus blazei, também conhecido popularmente como "Cogumelo do Sol", é de ocorrência natural nas regiões serranas da Mata Atlântica do sul do Estado de São Paulo, Município de Piedade e, segundo relatos de produtores, a espécie nativa foi coletada inicialmente por um agricultor e estudioso (Sr. Furumoto), que a cultivou entre as décadas de 60 e 70. Na época, algumas amostras foram levadas para o Japão com o interesse em estudar suas propriedades medicinais. Devido às condições climáticas favoráveis ao cultivo desse cogumelo, matrizes reproduzidas no Japão foram enviadas de volta ao Brasil e, desde então, várias técnicas de produção têm sido adaptadas, sempre com base no cultivo de champignon (Agaricus bisporus). Somente a partir de 1990 o cultivo comercial desse cogumelo teve início, de forma muito rudimentar e artesanal (Braga et al., 1998).

O valor nutritivo dos cogumelos é superior ao de diversas hortaliças. Seu conteúdo em proteínas é relativamente alto, alcançando de $1,5 \%$ a $6 \%$ de sua massa fresca, de acordo com as diferenças entre espécies. A idade, o ambiente, o local e a natureza do substrato de cultivo também influenciam seu conteúdo protéico. Geralmente, os cogumelos jovens são mais ricos em proteínas que os mais maduros ou abertos (Braga et al., 1998).

Braga et al. (1998) ressaltaram que a utilidade mais importante dos cogumelos na medicina é a sua ação antitumoral. Segundo os autores, a procura de substâncias e métodos que potencializem o sistema imunológico do corpo humano, de forma a induzir uma resistência sem causar efeitos colaterais deletérios ao organismo, tem sido uma das mais importantes buscas da ciência para a cura do câncer.

Herrera (2001) cita que é possível entender a lógica dos efeitos dos cogumelos como potencializadores imunológicos observando o seu ciclo de vida. Estes ocupam escalas inferiores no ecossistema, desenvolvem-se em materiais deteriorados e em ambiente hostil. Durante a fase vegetativa ou micelial, excretam enzimas para digerir os nutrientes contidos nos materiais em decomposição, sendo que, antes de absorver esses nutrientes, eles preci- sam desativar os seus patógenos naturais. Por isso, são muito hábeis para expelir substâncias químicas indesejáveis e contaminantes, que são absorvidas durante a digestão. Conforme o autor, a maior parte dos estudos sobre os benefícios dos cogumelos para a saúde humana enfoca suas propriedades de estímulo imunológico.

Osaki et al. (1994) realizaram alguns ensaios para estudar as substâncias antimutagênicas e bactericidas dos corpos de frutificação do Agaricus blazei e obtiveram resultados positivos. Ito et al. (1994) avaliaram a ação inibitória do complexo protéico/D-glucana (1-6) isolado do Agaricus blazei, num experimento para avaliar o mecanismo antitumoral de fibrosarcomas em ratos e observaram uma significativa remissão desses tumores. Ito et al. (1997) estudaram os efeitos antitumorais, em ratos, de um novo complexo protéicopolissacarídico preparado com Agaricus blazei, e verificaram a inibição do crescimento tumoral.

\subsection{O cultivo do Agaricus blazei}

O consumo brasileiro de Agaricus blazei ainda é muito baixo, porém há grande expectativa em relação ao potencial de uso medicinal desse cogumelo, onde se espera que outros segmentos, como as indústrias farmacêutica e alimentícia, possam participar aumentando a pesquisa, o consumo e, consequentemente, a produção (Braga, 1999).

O cogumelo Agaricus blazei é um saprófita secundário. Isso significa que, ao contrário de outros cogumelos, como o Shiitake (Lentinula edodes), - Maitake (Grifola frondosa) e o Reishi (Ganoderma lucidium), que são saprófitas primários, ele pertence ao grupo dos decompositores secundários, aqueles que não podem degradar componentes lignocelulósicos complexos, e, por isso, necessitam de uma segunda fase de compostagem para se desenvolver (Herrera, 2001).

Por tratar-se de uma cultura recente e dada a ausência de pesquisas, o cultivo de Agaricus blazei no Brasil ainda é praticado de forma empírica e sem embasamento técnico pela maioria dos produtores. Esse fato tem tornado o cultivo um negócio de risco, pouco produtivo e de alto custo. A maior produção de Agaricus blazei encontra-se no Estado 
de São Paulo, onde é explorado principalmente nas épocas de primavera e verão, em condições de cultivo não protegido (Braga, 1999).

O cultivo de A. blazei baseia-se nas técnicas utilizadas para a produção do champignon e envolve as seguintes etapas (Vedder, 1991; Eira e Minhoni, 1997):

1. Preparo do substrato de Cultivo (compostagem);

- Fase I da compostagem (“outdoor”);

- Fase II da compostagem (pasteurização e condicionamento “indoor”);

2. inoculação ou "semeadura";

3. colonização do substrato inoculado ou "corrida do micélio";

4. cobertura do substrato;

5. produção;

6. processamento.

\subsection{Produção de inoculantes}

Os fungos se reproduzem por intermédio de esporos ou assexuadamente (reprodução vegetativa), pela multiplicação de qualquer fragmento do corpo de frutificação ou do micélio.

A reprodução sexuada inicia-se pela germinação do esporo originado das basídias localizadas nas lamelas sob o chapéu, produzindo filamentos denominados de hifas. As hifas multiplicam-se no solo ou sobre outro substrato, ou ainda no laboratório, em meio de cultura, formando micélio. Pela união de duas hifas de sexualidades diferentes mas compatíveis entre si, forma-se o micélio secundário, onde ocorre o pareamento dos núcleos de hifas diferentes e, sob condições ambientais favoráveis, forma-se o micélio terciário que dará origem às basídias onde ocorre a fusão nuclear, sendo este processo denominado de cariogamia seguido pela meiose que originará os basidiósporos (Eira e Braga, 1997).

A reprodução assexuada ou vegetativa ocorre por multiplicação de qualquer fragmento do cogumelo, mantido sobre um substrato favorável e em condições adequadas, principalmente em relação à umidade e temperatura. Nessa fase, o fungo ocorre como micélio vigoroso e, pela reunião de hifas, formam-se estruturas rizomórficas (cordões de hifas macroscopicamente visíveis) (Eira e Braga, 1997).

\subsection{Produção de Matrizes primárias}

Existem basicamente dois métodos para fazer a multiplicação de Agaricus e de outros cogumelos: por meio de fragmentos do basidiocarpo (via vegetativa) ou através de esporos (isolamento monospórico e/ou multiespórico). Entretanto, atualmente estão sendo desenvolvidas novas tecnologias para produção de matrizes primárias que incluem a fusão de protoplasmas e cruzamentos (Braga et al., 1998).

\subsection{Produção de Matrizes secundárias}

A matriz secundária é obtida pela transferência de pequenos fragmentos de micélio da matriz primária para frascos contendo substrato do tipo grãos ou fibras (composto). Segundo Eira e Braga (1997), essas matrizes secundárias serão usadas como fonte de inóculo para a produção de grãos colonizados ou "spawn”, que proporcionarão as seguintes vantagens:

- Adaptação da matriz primária ao substrato "grãos” contribuindo para a redução do período de colonização desse substrato;

- redução no nível de contaminações dos grãos colonizados;

- aumento de rendimento na produção de grãos colonizados, pois com um tubo de ensaio (matriz primária) consegue-se inocular cerca de 10 frascos de $500 \mathrm{ml} \mathrm{com}$ substrato para matriz secundária e com um frasco de matriz secundária, consegue-se inocular cerca de 40 frascos ou sacos de polipropileno (PP) ou polietileno de alta densidade (PEAD) para produção de grãos colonizados;

- maior facilidade durante o processo de inoculação, com fins de produção de grãos colonizados pelo fungo. 


\subsection{Produção de grãos colonizados}

Quando as hifas de cogumelos crescem em grandes quantidades de substratos (grãos, materiais celulósicos ou minerais enriquecidos), e em condições estéreis de laboratório, recebem o nome de inoculante, grãos colonizados ou "spawn" (Eira e Minhoni, 1997). Esses grãos colonizados são preparados em laboratório, sob condições estéreis e sobre uma grande variedade de substratos, devendo-se considerar principalmente os aspectos econômicos, produtividade e qualidade dos cogumelos. As duas formas mais comuns para a produção de inoculantes são em grãos e em composto. Uma terceira forma de produzir "spawn", chama-se “pellet” que é um mineral expandido em temperatura maior que $100^{\circ} \mathrm{C}$. Para usá-lo, este é impregnado com solução de nutrientes adequados. "Pellet spawn”, é facilmente dispersado e o custo de produção é bastante reduzido podendo ser armazenado por um longo período (Eira e Minhoni, 1997).

\subsection{Compostagem}

Para que o cogumelo cresça e se reproduza, é necessário a criação de um ambiente favorável, fornecendo condições e nutrientes adequados. A compostagem pode ser definida como uma decomposição aeróbia controlada de substratos orgânicos em condições que permitem atingir temperaturas suficientemente elevadas para o crescimento de microrganismos termofílicos. $\mathrm{O}$ aumento de temperatura surge como resultado da liberação de calor na degradação microbiológica dos substratos. O resultado desse processo é um produto denominado composto (Braga, 1999). O composto clássico é formulado à base de palha de gramíneas e esterco fresco de cavalo proveniente das camas das estrebarias, desde que este último corresponda a $20-30 \%$ do total da massa do composto. Essa composição apresenta quase todos os nutrientes necessários ao desenvolvimento do Agaricus, exceto o nitrogênio, que necessita de suplementação; essa varia de acordo com o material que constitui o composto. Dependendo do material utilizado, costuma-se adicionar farelos como fonte orgânica de nitrogênio, super- fosfato, sulfato de amônio ou uréia, além do calcário como corretivo do $\mathrm{pH}$ e sulfato de cálcio (gesso) como estruturador (Braga, 1999).

A fase 1 da compostagem acontece com o material empilhado (outdoor). O objetivo é manter as reações bioquímicas ativas, por meio da umidade adequada. O processo de fermentação começa na periferia do monte, atingindo de $10 \mathrm{a} 20 \mathrm{~cm}$, onde há melhores condições aeróbias e termofílicas (Braga et al., 1998).

Depois de 15 a 20 dias, o composto está totalmente fermentado, e deve ser transferido para o túnel de pasteurização onde, com o próprio calor residual da massa compostada, irá se manter com a temperatura na faixa de $55-60^{\circ} \mathrm{C}$. É uma fase importante para a eliminação de insetos, pragas e organismos indesejáveis que não foram eliminados na fase 1 (Pascholati et al.,1998).

O processo de preparo do substrato é a parte mais dispendiosa do cultivo (Molena, 1996; Eira e Braga, 1997), por isso procuram-se novos métodos de compostagem rápida, que abreviem as operações e o tempo de ocupação das instalações, racionalizem materiais, evitando perda de nutrientes, minimizem o impacto ambiental e ofereçam produtividade e confiabilidade maiores.

\subsection{Inoculação de grãos colonizados}

O cultivo do cogumelo pode ser realizado por diferentes sistemas. Os mais comuns são a colonização em sacos plásticos , em "camas de cultivo" ou diretamente no solo. Os dois primeiros sistemas são realizados em local protegido, o que permite maior controle das condições ambientais e prolongamento do período produtivo (Pascholati et al., 1998).

\subsection{Camada de Cobertura}

A camada de cobertura é a etapa de cultivo em que se adiciona terra desinfestada e desinfectada sobre o substrato colonizado, pois materiais contaminados por pragas indesejáveis devem ser tratados para manter-se o cultivo. As principais funções 
da camada de cobertura são proporcionar suporte físico para o desenvolvimento do corpo de frutificação e uniformizar a superfície, regular a temperatura entre o substrato e o ambiente, reter água para evitar o ressecamento do substrato, fornecer água para o basidiocarpo, permitir trocas gasosas e funcionar como barreira de proteção contra microrganismos competidores ou patogênicos (Colauto, 1998).

\subsection{Coleta e limpeza dos corpos de frutificação}

Inicia-se, em média, de 21 a 30 dias após ser adicionada a camada de cobertura. A produção pode se estender por até 6 meses, mas é economicamente viável até o terceiro ou quarto mês. Durante esse período, haverá picos de produção, em média a cada 25 dias. Depois de coletados, os cogumelos devem ser lavados, pois, como ficam no solo, na haste, junto às raízes, concentra-se terra que deve ser retirada com o auxílio de jato de água, uma escova ou uma faca. O resultado final é um cogumelo branco, pronto para a desidratação (Pascholati et al., 1998).

\subsubsection{Desidratação}

A desidratação deve ser realizada imediatamente após a coleta. Os cogumelos são cortados ao meio longitudinalmente e colocados cuidadosamente em bandejas, em seguida, devem são levados ao desidratador, onde são submetidos a uma temperatura constante de $45^{\circ} \mathrm{C}$ a $55^{\circ} \mathrm{C}$, dependendo da qualidade, por um período de $8 \mathrm{~h}$ a $14 \mathrm{~h}$ (Pascholati et al.,1998).

\subsubsection{Embalagem e comercialização}

Os cogumelos são embalados em sacos de polipropileno e pesados, sendo que cada unidade deve ter de $250 \mathrm{~g}$ a $1 \mathrm{~kg}$. Coloca-se silica-gel $(9 \mathrm{~g}$ para cada $250 \mathrm{~g}$ de cogumelos) na embalagem para não haver aumento de umidade. Como medida de segurança, podem ser utilizados sacos duplos (Pascholati et al.,1998).

\section{Material e métodos}

Os experimentos para a obtenção de inoculantes e produção de grãos inoculados pelo fungo foram realizados em uma das etapas do trabalho, no Módulo de Cogumelos do Departamento de Defesa Fitossanitária da Faculdade de Ciências Agronômicas (FCA), Campus de Botucatu UNESP, Área de Biotecnologia e Microbiologia Agrícola. Foram selecionados alguns cogumelos sadios, em perfeitas condições para a realização da multiplicação por via vegetativa.

Foram realizadas visitas técnicas a alguns produtores de cogumelo do sol, observando-se as fases de produção, desde o composto até o produto final, obtendo-se amostras de materiais, as quais se encontravam fatiadas, desidratadas e todas pertencentes ao mesmo ciclo de coleta. As amostras foram reduzidas a pó e acondicionadas em dessecador para determinação das análises laboratoriais.

A determinação da composição química do cogumelo do sol - Agaricus blazei, em diferentes partes e tamanhos do corpo de frutificação, foram realizadas no Laboratório de Tecnologia de Alimentos da Universidade Estadual de Ponta Grossa UEPG.

Numa primeira etapa, determinou-se a composição química de duas linhagens de cogumelo do sol.

Na segunda etapa do trabalho, as análises da composição química foram mais complexas. O material foi coletado de produtores da cidade de Castro-Pr, produzidos na mesma época do ano; foram selecionados por tamanho e posteriormente submetidos a um corte na estrutura, separando-os em píleo e estirpe. Foram realizadas análises físico-químicas da matéria prima, tais como: determinação de cinzas, umidade, lipídios, proteínas e fibras, segundo as normas analíticas do Instituto Adolfo Lutz (1985).

\subsection{Produção de inoculantes utilizando técnicas por via vegetativa}

Nessa técnica a produção da matriz, ou 
inóculo, consistiu em transferir o fragmento do basidiocarpo para um meio de cultura (BDA). Para tanto foi necessário selecionar um corpo de frutificação de Agaricus blazei saudável e limpo. Em uma câmara asséptica, foram utilizados bico de Bunsen e álcool para flambar todos os materiais (pinças, alças, placas de Petri). Fragmentos de 2 a $5 \mathrm{~mm}$ foram retirados da parte interna do cogumelo e colocados no centro do meio de cultura contido nas placas de Petri. Essa operação foi feita com muito cuidado e rapidez para que fossem evitadas contaminações. As placas inoculadas foram levadas à estufa de $25^{\circ} \mathrm{C}$ por 15 dias. Após esse período o meio de cultura deveria estar coberto pelo micélio do fungo inoculado, sendo dada preferência ao micélio rizomórfico.

Pesquisas realizadas no Módulo de Cogumelos Comestíveis, FCA / UNESP, ressaltam que a utilização de meios de cultura muito ricos e completamente diferentes dos substratos de cultivo, podem levar à seleção de mutantes nutricionais, que podem perder características microbiologicamente importantes (Braga, 1999).

Para a formulação do substrato foram misturados os seguintes materiais: bagaço de cana (34\%), feno (22\%), esterco de estrebaria (25\%), farelo de soja (10\%), calcário (4,0\%), sulfato de amônia $(1,25 \%)$, uréia $(0,75 \%)$, super fosfato simples $(1,0 \%)$, gesso $(2,0 \%)$.

No Módulo de Cogumelos utilizou-se como meio de cultura, 30 a $50 \mathrm{~g}$ de composto (seco), $15 \mathrm{~g}$ de ágar e $12 \mathrm{~g}$ de dextrose. O composto foi adicionado em $800 \mathrm{~mL}$ de água destilada e fervida por 10 minutos, posteriormente passou por uma peneira e foi envasado em um vidro de $500 \mathrm{~mL}$; em seguida foi esterilizado em autoclave por 30 minutos a $121^{\circ}$ C e $1 \mathrm{~atm}$. No dia seguinte, adicionou-se mais 500 $\mathrm{mL}$ de água destilada e foi novamente autoclavado por 30 minutos. Após o resfriamento em câmara de fluxo laminar, adicionou-se o ágar e a dextrose, devidamente esterilizados. O líquido foi vertido em placas de Petri, que foram mantidos em local asséptico até que fossem inoculados para obtenção da matriz primária.

\subsection{Produção de Matrizes secundárias}

As placas contendo a matriz primária, foram multiplicadas em outras placas com o mesmo meio de cultura; estas passaram pelo processo de esterilização durante 2 horas a 1 atm e $121^{\circ} \mathrm{C}$. Após resfriamento, as placas foram inoculadas em condições assépticas com a matriz primária e incubadas à temperatura de $25^{\circ} \mathrm{C}$ durante 20 a 30 dias, período suficiente para que ocorresse a colonização total no meio de cultura.

\subsection{Produção de substrato à base de grãos de trigo}

Para a preparação do "spawn” em grãos, foram utilizados frascos com tampa e sacos de polipropileno, sendo que esses recipientes suportam o processo de esterilização. Procedeu-se a fervura de 10 kg de grãos de trigo em 15 litros de água por 15 minutos e, em seguida, permaneceram em imersão sem aquecimento por mais 15 minutos. Posteriormente a água foi escorrida e os grãos colocados em uma betoneira até que secassem parcialmente. Foram adicionados $120 \mathrm{~g}$ de gesso e $30 \mathrm{~g}$ de carbonato de cálcio, para evitar que os grãos ficassem demasiadamente aderidos, e o calcário para fazer a correção do $\mathrm{pH}$. Ainda quentes os grãos foram colocados nos frascos e sacos de polipropileno até cerca de $2 / 3$ do seu volume e suas bocas vedadas com algodão e fita adesiva, permitindo assim a passagem de oxigênio para o interior dos frascos; após isto, foram cobertos com papel e esterilizados em autoclave.

\subsection{Inoculação do substrato para produção dos grãos colonizados}

Os frascos com o substrato à base de grãos de trigo esterilizados foram inoculados com pequenos fragmentos da matriz secundária, através do uso da câmara de fluxo laminar, evitando assim contaminação e perda dos grãos. Após a inoculação do substrato "grãos”, os frascos e sacos de polipro- 
pileno foram incubados à temperatura de $25^{\circ} \mathrm{C}$ por 30 dias, quando então já estariam prontos para uso dos fungicultores.

\section{Análise da composição química do píleo e estirpe dos corpos de frutificação de Agaricus blazei}

O material para a determinação da composição química foi seco e selecionado por tamanho: pequenos, com aproximadamente $4 \mathrm{~cm}$ de comprimento, e os cogumelos considerados grandes, medindo de 5 a $12 \mathrm{~cm}$ de comprimento. Após, foram submetidos a um corte, dividindo-os em píleo e estirpe, caracterizando então a composição química de ambas as partes separadamente. Todas as análises foram feitas em duplicatas.

A umidade foi determinada gravimetricamente após secagem em estufa a $105^{\circ} \mathrm{C}$ por 5 horas. $\mathrm{O}$ teor de lipídeos foi analisado gravimetricamente após extração com éter de petróleo, utilizando-se o aparelho extrator de Soxhlet com aquecimento em mantas elétricas (Instituto Adolfo Lutz, 1985). As proteínas foram quantificadas pelo método de microkjeldahl (Instituto Adolfo Lutz, 1985). Após a suspensão em água deionizada de uma quantidade de corpos de frutificação triturados, mediu-se o pH com uso do potenciômetro e determinou-se a acidez por titulação com $\mathrm{NaOH}$ 0,1N. As fibras foram quantificadas segundo o método de Weender (Ascar, 1985). As amostras foram submetidas a uma digestão com solução ácida por 30 minutos seguida de digestão com solução básica por mais 30 minutos, o material resultante da filtragem foi considerado fibra (Ascar, 1985). Para a quantificação das cinzas, as amostras foram submetidas à temperatura de $550^{\circ} \mathrm{C}$ em mufla, por 6 horas (Instituto Adolfo Lutz, 1985). No caso dos carboidratos presentes nas amostras, obteve-se o resultado por diferença.

\section{Resultados e discussão}

O meio de cultura obtido através da adição do extrato de composto, proporcionou um bom desenvolvimento do micélio, tanto nas placas quanto no substrato de cultivo, pois houve uma rápida adaptação do fungo no ambiente (composto).

A obtenção de inoculante (grãos colonizados pelo fungo), foi feita através do método de reprodução vegetativa, pela multiplicação de um fragmento do corpo de frutificação. O preparo do inoculante exigiu assepsia no laboratório, esterilização dos materiais a serem utilizados, bem como do meio de cultura e, mão de obra qualificada. Apesar de possuir uma tecnologia já estabelecida e de fácil acesso, a produção de inoculantes deve ser considerada como um setor exclusivo, e não uma das etapas com que o produtor de A. blazei deva se preocupar e investir.

Os frascos foram inoculados em condições assépticas com a matriz primária e incubados à temperatura de $25^{\circ} \mathrm{C}$ durante 20 a 30 dias, período suficiente para que ocorresse a colonização total do substrato. Obtidas as matrizes secundárias, estas foram usadas como fonte de inóculo para a produção de grãos de trigo colonizados pelo fungo. As vantagens que podemos obter com a produção de matrizes secundárias são:

- Adaptação da matriz primária ao substrato (grãos de trigo);

- redução no nível de contaminações dos grãos colonizados;

- aumento de rendimento na produção de grãos colonizados, pois com um tubo de ensaio ou placas de Petri, contendo matriz primária, conseguiu-se inocular cerca de 10 frascos de $500 \mathrm{~mL}$ com substrato para matriz secundária, e aproximadamente 40 sacos de polipropileno, para produção de grãos de trigo colonizados por A. blazei.

Os frascos contendo substrato à base de grãos de trigo esterilizados foram inoculados com pequenos fragmentos da matriz secundária. A cada sete dias após a inoculação estes frascos eram agitados, permitindo uma redistribuição do micélio no substrato. Após a inoculação do substrato semente, os frascos foram incubados à temperatura de aproximadamente $25^{\circ} \mathrm{C}$ por mais 30 dias. 
A partir dos frascos colonizados, foram feitas inoculações em sacos de polipropileno, contendo grãos de trigo esterilizados. Após a inoculação do substrato semente, os sacos foram incubados à temperatura de aproximadamente $25^{\circ} \mathrm{C}$ por mais 30 dias, ou até a total colonização, estando prontos então para uso dos fungicultores.

Na primeira etapa, a avaliação físico-química das amostras de duas linhagens de cogumelo do sol apresentou similaridade com a composição média apresentada na literatura (Braga et al., 1998; Copercom, 1998), conforme mostrado na Tabela 1.

Tabela 1- Composição química de linhagens de Agaricus blazei Murril (em base seca).

\begin{tabular}{lcccccccc}
\hline Amostra & \%MS & \%proteínas & \%fibras & \%cinzas & $\mathrm{pH}$ & $\begin{array}{l}\text { Acidez } \\
\text { (N/100g) }\end{array}$ & \%lipídios & \% Carboidratos \\
\hline AbM (a) & 12,0 & 39,80 & 9,65 & 7,75 & 6,55 & 3,75 & 0,89 & 41,91 \\
AbM (b) & 12,4 & 37,00 & 9,41 & 7,57 & 6,56 & 3,65 & 0,80 & 45,22 \\
Jun-17 (a) & 15,0 & 34,80 & 8,56 & 7,63 & 6,70 & 2,95 & 1,15 & 47,86 \\
Jun-17 (b) & 16,3 & 38,00 & 7,66 & 6,99 & 6,68 & 2,85 & 1,13 & 46,22 \\
Copercom* & - & 39,68 & 7,35 & 7,89 & - & - & 3,68 & 41,41 \\
\hline
\end{tabular}

*Copercom (1998); (a) e (b) correspondem a repetições.

Pode-se verificar na Tabela 1 , que o A. blazei linhagem AbM, apresentou teores de fibras e cinzas um pouco superiores enquanto na variante Jun-17 as concentrações de carboidratos e de lipídios fo- ram mais elevadas.

A Tabela 2 apresenta os valores médios, resultantes de dois tamanhos de cogumelos, em partes diferentes do basidiocarpo.

Tabela 2 - Composição centesimal de duas partes do corpo de frutificação de A.blazei desidratado (GRANDES ${ }^{1}$ e pequenos ${ }^{2}$ ) - resultados apresentados em base seca

\begin{tabular}{lcccc}
\hline & PÍLEO $^{1}$ & ESTIRPE $^{1}$ & píleo $^{2}$ & estirpe $^{2}$ \\
\hline Umidade & & g/100g & & \\
Carboidratos* & 8,50 & 8,35 & 11,40 & 9,63 \\
Cinzas & 33,14 & 54,22 & 22,88 & 50,80 \\
Lipídios & 9,16 & 7,15 & 9,68 & 7,88 \\
Proteínas & 2,04 & 0,82 & 1,98 & 0,98 \\
Fibras & 46,80 & 27,68 & 55,16 & 31,06 \\
\hline
\end{tabular}

* Diferença: carboidratos = 100- (\% proteína + \% lipídios + \% cinzas + \% fibras $)$ 
O valor nutritivo dos cogumelos é comparável ao de algumas hortaliças. Seu conteúdo em proteínas é relativamente alto, alcançando de 1,5 a 6\% do peso fresco, confirmando seu potencial nutricional, no entanto as diferenças entre o tamanho dos cogumelos são evidentes.

De acordo com Braga et al., (1998), a idade, o ambiente, o local e a natureza do substrato de cultivo também exercem grande influência em seu conteúdo protéico. Em termos percentuais, geralmente, os cogumelos jovens são mais ricos em proteínas que os maduros

Verificou-se na Tabela 2, que o teor de carboidratos foi mais elevado na estirpe dos cogumelos maiores; esses valores foram superiores aos do píleo que apresentaram um teor de carboidratos de 33,14 e 22,88\% respectivamente. Ambos os tamanhos de cogumelos apresentaram uma porcentagem menor de resíduos minerais na estirpe. O píleo apresentou teor de lipídeos superior ao da estirpe. Para as fibras não houve grandes diferenças, pois apresentaram resultados diferentes entre tamanhos e estruturas dos cogumelos. Obteve-se maior quantidade de fibras no píleo dos cogumelos menores. $\mathrm{O}$ teor de proteínas foi elevado nos cogumelos menores, sendo encontrada principalmente no píleo com $55,16 \%$ (nos cogumelos menores) e $46,8 \%$ (nos maiores), confirmando seu potencial nutricional. $\mathrm{Na}$ estirpe o teor de proteínas foi encontrado em maior quantidade nos cogumelos menores.

\section{Conclusões}

Pelos resultados obtidos nas análises de Agaricus blazei Murril, podem ser extraídas as seguintes conclusões:

- A análise da composição química de Agaricus blazei revelou que há diferenças entre as duas linhagens de cogumelos, sendo a linhagem AbM mais rica em fibras e minerais, enquanto que a linhagem Jun17 apresentou teor mais elevado de carboidratos;
- Na análise realizada com diferentes tamanhos de cogumelos revelou-se que, os cogumelos menores, apresentaram maior teor de proteínas, principalmente na região do píleo, e nos cogumelos maiores, maior concentração de carboidratos, principalmente na região da estirpe.

\section{REFERÊNCIAS}

1 ASCAR, J.M. Alimentos: aspectos bromatológicos e legais. Análise percentual. V. 1, São Leopoldo, 1985. 327p.

2 BANO, Z.; RAJARATHNAM, S. Pleurotus mushrooms. II. Chemical composition, nutritional value, post-harvest physiology, preservation, and role as human food. Crit Rev Food-Sci-Nutr, v.27(2), p. 87-158, 1988.

3 BRAGA, G.C; Productivity Agaricus blazei Murril in relation to the cultivation environment, the substratemass and the casing layer. Botucatu: Departamento de Defesa Fitossanitária, Faculdade de Ciências Agronômicas, Unesp p. 73, 1999. (Tese de Doutorado).

4 BRAGA, G.C.; EIRA, A.FL; CELSO, G.P., et al. Manual de cultivo de Agaricus blazei Murril “ cogumelo do sol”. Botucatu: Fundação de Estudos e Pesquisas Agrícolas e Florestais, 1998. 44p.

5 CHANG, S.T. A global strategy for the bioconversion of lignocellulosic biomass - a challenge of a "Non-green Revolution”. 1998. Disponível em <http:// www.zeri.uniosnabrueck.de/nongreeneng.htm> Acesso em: dez. 2001.

6 COLAUTO, N.B. Influência de Pseudomonas putida na indução de basidiocarpos em Agaricus spp. Botucatu: Departamento de Defesa Fitossanitária, Faculdade de Ciências Agronômicas, Unesp, 1998. 126p. (Tese de Doutorado).

7 COPERCOM. Valores nutricionais do Agaricus blazei Murril. In: Apostila de cultivo do Agaricus blazei Murril. Cooperativa dos Produtores de Cogumelos. Sorocaba, 1998. Disponível no site: http://www.terravista.pt/copacabana/4998/ agaricus-pt.htm., consultado em out/2001.

8 EIRA, A.F.; BRAGA, G.C. Manual do cultivo do “champignon” (Agaricus spp). Botucatu, SP: Fundação de Estudos e Pesquisas Agrícolas e Florestais, 1997. 45p.

9 EIRA, A.F.; MINHONI, M. T. A. Manual teórico prático do cultivo de cogumelos comestíveis. Botucatu: Fundação de Estudos e Pesquisas Agrícolas Florestais, 1997. p.34-46. 
10 ELLIOTT, T.J. Genetic engineering and mushrooms. Mushroom Growers Assoc. conference. p. 528-9, 1987.

11 HERRERA, O.M.; DOMINGUES, M.V.E. Produção e comercialização do cogumelo Agaricus blazei. Botucatu, 2001, 126p.

12 HERRERA, O.M. Produção, Economicidade e Parâmetros Energéticos do Cogumelo Agaricus blazei: Um Enfoque na cadeia Produtiva. Botucatu, Departamento de Defesa Fitossanitária, Faculdade de Ciências Agronômicas, Unesp, 2001. 183p. (Tese de Doutorado).

13 IAL Normas Analíticas do Instituto Adolfo Lutz. 3. ed., São Paulo: Instituto Adolfo Lutz, 1985. 533p. (Volume 1, Métodos Químicos e Físicos para Análise de Alimentos).

14 ITO, H.; SHIMURA, K.; KAWADE, M. Antitumor effects of a new polysacharide protein complex (ATOM) prepared from Agaricus blazei (Iwade strain 101) “Himematsutake”and its mecnanisms in tumor-bearing mice. Anticancer Res, 1997 Jan;17: 277-284.
15 MOLENA, O. O Moderno Cultivo de Cogumelos. São Paulo: Nobel, 1996. 170p.

16 OSAKI, Y.; KATO, T.;YAMAMOTO, K.; OKUBO, J.; MIYAZAKI, T. Antimutagenic and bactericidal substances in the fruit body of a Basidiomycete Agaricus blazei, Jun-17 Yugaku Zasshi, 1994 Mai;114(5):342-350.

17 PASCHOLATI, S.; SANGARLIN, J.R.; PICCININ, D. Cogumelos: cultivo e comercialização (Shiitake e Cogumelo do Sol). SEBRAE/MT, 1998 85p. (Coleção Agroindústria, v.17).

18 POPPE, J. Use of agricultural wast materials in the cultivation of mushrooms. In: International Congress on the Science and cultivation of Edible Fungi, 2000, Netherlands Anais, 2000.

19 SETTE, R.S. Qualidade Total na Agropecuária. Informe ESAL. Lavras: ESAL, n.5, 1994.

20 VEDDER, P.J.C. Cultivo Moderno Del Chapinõn. Madrid: Ediciones Mundi-Prensa, 1991. 370p. 